\title{
GIS-Based Multi-Criteria Evaluation Models for Selection of Suitable Sites for Pacific Oyster (Crassostrea gigas) Aquaculture in the Central Region of Vietnam
}

\author{
Nguyen Thanh Tung ${ }^{1}$ and Tong Phuoc Hoang Son ${ }^{2}$ \\ 1. Vietnam Institute of Fisheries Economics and Planning, Ministry of Agriculture and Rural Development, Hanoi 100000, Vietnam \\ 2. Institute of Oceanography, Vietnam Academy of Science and Technology (VAST), Khanh Hoa 650000, Vietnam
}

\begin{abstract}
Oysters are nutritious food organisms, rich in protein, minerals and vitamins. Production from Pacific oyster (Crassostrea gigas) aquaculture is increasing and supports the livelihoods of coastal communities. To ensure both success and long-term sustainability of oyster production, the determination of suitable sites is an important step in any aquaculture operation. This study applied GIS (Geographic Information System) based MCE (Multi-Criteria Evaluation) for locating suitable sites for Pacific oyster (Crassostrea gigas) farms in coastal regions in Central Vietnam. Remote sensing data were obtained viaMODIS (Moderate Resolution Imaging Spectroradiometer) and high resolution imagery from the Google Earth Engine, while oceanic data were obtained from HYCOM-NCODA (Hybrid Coordinate Ocean Model-Navy Coupled Ocean Data Assimilation) coupled with local hydrodynamic FEM (Finite Element Model) Hydrographic charts and GPS (Global Positioning System) data were used to extract required information layers for GIS based MCE for the suitable site selection of oyster farms. Six thematic layers of biophysical parameters were used to analysis MCE non-constraints including the depth, temperature, salinity, Chl-a (Chlorophyll-a) content, suspended matter concentration and velocity of sea current. Then, an MCE analysis with constraint was used to exclude the areas from suitability maps where oyster aquaculture could not be developed. They were conducted in two subgroups, biophysical subgroup (including un-suitable depth, un-suitable substratum and shore line types, potential regions prone to strong impact of natural disasters and environmental risks, sensitive habitats in MPAs (Marine Protection Areas), and social-infrastructural subgroups (including human settlement in urban area, wastewater system, industrial zones, piers, harbors etc.). A series of GIS models was developed to identify the most suitable areas for oyster culture using MCE with the estimating of factor score $\left(X_{i}\right)$ based on expert knowledge as well as calculating of Weighting $\left(W_{i}\right)$ based on Saaty's matrix relevant to the importance level of assessed factors in comparison. Suitability scores were ranked on a scale from 1 (least suitable) to 8 (most suitable). The best suitable sites for oyster aquaculture in coastal areas of the central region of Vietnam have been found. These study results confirmed that a GIS based MCE model is a powerful tool that supports site selection decision-making in aquaculture.
\end{abstract}

Key words: GIS, remote sensing, MCE, suitable site selection, Pacific oyster.

\section{Introduction}

Oysters are nutritious food organisms, rich in protein, minerals and vitamins. Their importance as food has helped numerous countries culturing them, to build up foreign exchange earnings. In Korea, for instance, oyster exports in 1982 contributed to about $54 \%$ of the total export of canned marine products to Canada,

Corresponding authors: Nguyen Thanh Tung, Ph.D, Doctor of Biology, main research field: biology. Tong Phuoc Hoang Son, Bachelor, Engineer of GIS-remote sensing, main research field: GIS-remote sensing.
Australia, Holland and Sweden. The Philippines was a significant exporter of oyster in Singapore's market until the early 1980's. About 180,000 kg of oyster meat valued at Peso 215 million was exported to Singapore in 1980. Foreign market for Philippine oysters includes many countries in the world. In Vietnam, Pacific oyster (Crassostrea gigas) is also a popular species being cultured in different regions in the coastal lagoons and bays of Central Vietnam.

Aquaculture is one of the fastest growing food-producing sectors, supplying approximately $47 \%$ 
of the world's seafood supply in 2009 [1]. The rapid growth of aquaculture has forced it to address environmental, social and economic issues in a unified way to achieve sustainability. Combined with the social aspects of siting shellfish farms is the consideration of environmental parameters in which cultured species of interest are capable of thriving. Bivalve mollusks derive their energy for growth and necessary life functions through filter feeding; the active removal of phytoplankton, detritus and POM (Particulate Organic Matter) from the water column. Many concomitant factors affect bivalve feeding, nutrition, growth and survival including both biotic and abiotic influences (e.g. Chl-a (Chlorophyll-a) content, organic particulate matter concentration, water velocity or flow rate, water temperature, dissolved oxygen and $\mathrm{CO}_{2}$ concentrations, $\mathrm{pH}$ and sediment characteristics) [2]. Siting farms within appropriate environmental parameters allows for maximum crop yield, benefiting the farmer and the local economy.

GIS (Geographic Information System) coupled with remote sensing provides the ability to display spatially complex data and competing demands on coastal space, allowing managers to better understand the needs of user groups, farmers to maximize potential profits and the protection of critical habitats. GIS based MCE (Multi-Criteria Evaluation) is a method to support decision-making based on the concept of multi-layer space environment (including information layers on the environment, economy and society). MCE analysis includes a set of evaluation criteria which are quantitative indicators of the extent to which the decided objective needs to be made [3]. An overview of spatially related issues using GIS applications in aquaculture was carried out by Kapetsky and Aguilar-Manjarrez [4] which included finfish cage culture (13 applications) and shellfish culture (24 applications). By managing mapping, remote sensing and GIS applications separately, the important role of each technique in spatial analysis for development and management of aquaculture was emphasized. Altogether, GIS aimed at aquaculture development accounted for more than 50 percent of all applications, and the sub-issues most frequently addressed were: (i) suitability of the site and zoning and (ii) strategic planning for development. GIS applications in this main issue category are carried out as a prelude to aquaculture development. The application of GIS-based MCE has developed worldwide and has reached many achievements in aquaculture, particularly in bivalve farming and oyster culture towards long-term sustainability [2, 4, 5-13]. In this work, we attempt to apply GIS based MCE for identifying suitable sites for Pacific oyster (Crassostrea gigas) farming in the coastal waters of Central Vietnam.

\section{Data and Methodology}

\subsection{Study Area}

The area of studyis located in coastal waters of the central region of Viet Nam and is limited by Da Nang in the north and Binh Thuan Province to the South (Fig. 1). Coastal areas of this region include seven provinces and one municipality city, making it a group with the greatest potential in developing the economy and tourism of the country. The coast is divided by mountains that reach the sea and create a series of coastal bays and lagoons. The seasonal oceanographic characteristics of surface water of the SCS (South China Sea) have been studied since the Naga expedition in 1959-1961 [14]. Central Viet Nam has strong seasonal patterns of monsoon influence. In these surveys, a noticeable finding included coastal upwelling activity in the south central Viet Nam [14]. Some studies revealed patterns of upper circulation $[15,16]$ using models from climatological and satellite data while in situ data were rare. However, these studies identified the clear surface circulation pattern of the southern part of the SCS with clockwise/counterclockwise gyres. These features were well indicated with salinity and temperature. The 


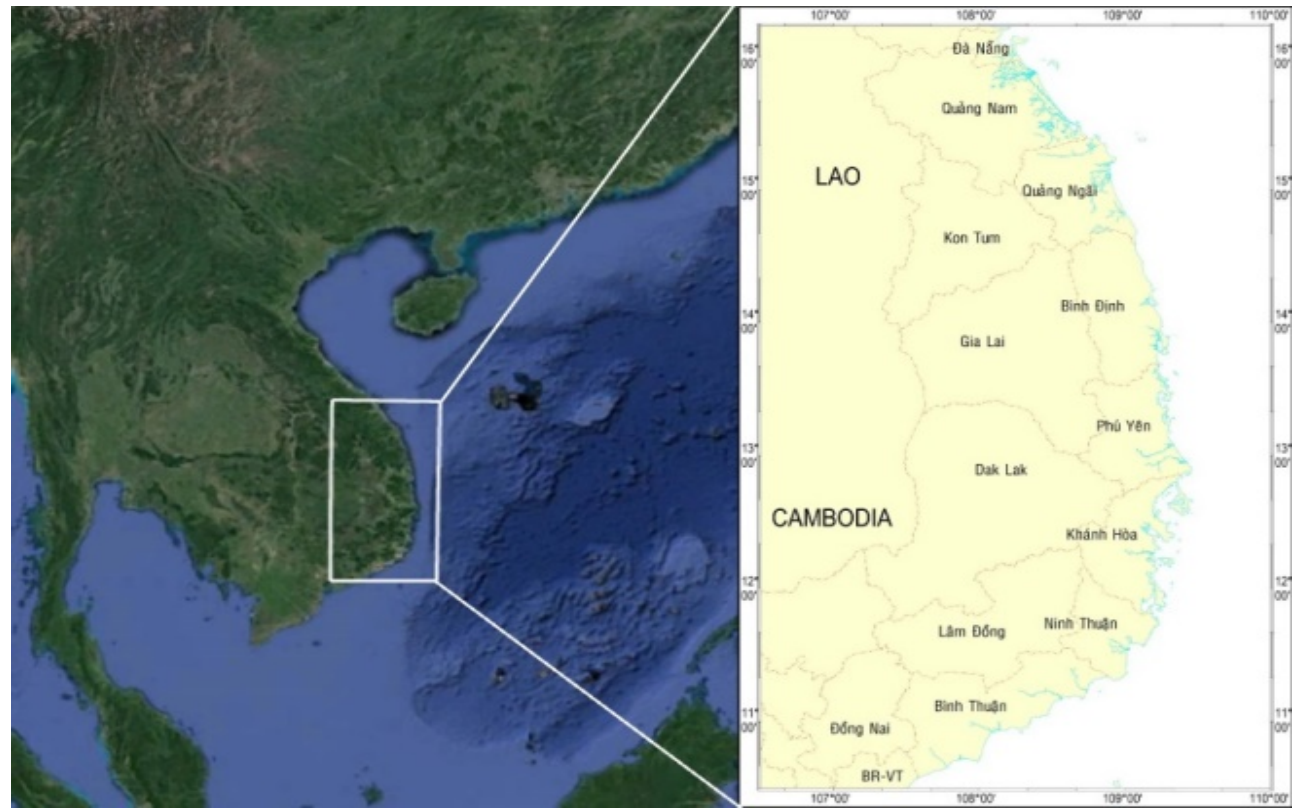

Fig. 1 Study area - the coastal waters in Central region of Vietnam (including 8 coastal provinces) where it needs to determine suitable sites for Pacific oyster (Crassostrea gigas) aquaculture.

western boundary current (Viet Nam coastal jet) was also seasonally varied with strong, broad and northeast ward during the southeast monsoon $[16,17]$. The monsoons introduce upwelling both in south central coast of Viet Nam [17] and in the north Sunda shelf [18-20] generating high productive areas in the south of SCS. SST (Sea Surface Temperature) in coastal waters of this region varies from $23{ }^{\circ} \mathrm{C}$ in January-February to $32{ }^{\circ} \mathrm{C}$ in July-August. Salinity is relatively stable, ranging from $31 \%$ to $34 \%$. Chl-a levels are very high during the spring bloom in February to March, but relatively low $\left(<1 \mathrm{mg} / \mathrm{m}^{3}\right)$ during the summer (i.e. July-August). Wind conditions vary seasonally; winds are southeasterly in summer and northwesterly in winter. Coastal waters of Central Vietnam are also influenced by terrestrial materials from river discharge as well as urban and industrial effects.

The formation of coastal bays and lagoons creates favorable conditions for the development of marine cage culture of bivalves and lobster in the Central region of Vietnam. In terms of oyster farming, Pacific oyster (Crassostrea gigas) is the most popular species being farmed in different regions in the coastal lagoons, bays in central Vietnam such as Cua Lo, An Hoa estuaries (Quang Nam province); Sa Ky, Sa Huynh coastal water (Quang Ngai province), Degi, Thi Nai lagoons (Binh Dinh), Cu Mong lagoon, Xuan Dai bay (Phu Yen province); Nha Phu lagoon (Khanh Hoa province), Vinh Hy lagoon (Ninh Thuan province). Pacific oyster is widely cultivated by individuals, companies and fishermen associations.

\subsection{Identification of Criteria and Data Collection}

For mariculture, optimal site selection is considered based on physico-chemical properties of water masses. They include parameters such as temperature, salinity, dissolved oxygen content and water circulation, ventilation level and the ability of water exchange, pollution levels, eutrophication, the food source (through concentration of Chl-a), shielding ability, depth and type of substrate.

According to a study on the development of bivalve culture, monthly shell growth has significant correlation with the original size, water temperature, salinity and phytoplankton biomass [21]. The fouling organisms, predation and disease should be considered for exclusion. The hydrodynamic conditions can 
contribute to productivity through the food provision and seed diffusion [22], but it can also cause disadvantage to oyster farming when current velocity is too high or too low [23]. Oysters are bivalve, filter feeding animals, with their food including bacteria, protozoa, diatoms, the larvae of the species of vertebrate and organic detritus [24]. For Pacific oyster (C. gigas), the site selection depends mainly on temperature, salinity and abundance of food sources $[21,23,25]$. These factors have a strong influence on the different phases of the life cycle of oyster (i.e. gametogenesis, reproduction, larval development, and grow-out phases) [25]. Factors that adversely affect the growth and development of the oysterinclude unfavorable water flow (velocity is too high or too low) [23]. Inappropriate substrata and unsuitable depth are inconsistent with the ecology of the oyster, including predators, disease and pollution [23]. In addition, social and infrastructural factors also affect farming operations. Therefore, these parameters were used for identifying suitable sites for oyster culture in coastal waters of Central Vietnam.

The primary data sources used included MODIS (Moderate Resolution Imaging Spectroradiometer) and high-resolution imagery obtained from the Google Earth Engine, hydrographic charts and GPS (Global Positioning System) data. SST data were derived from the MODIS-Aqua sensor as level-2B data with $1 \mathrm{~km}$ resolution from OCx (Ocean Color) website of NASA (https://oceancolor.gsfc.nasa.gov/cgi/). Daily SST product was processed using the split window algorithm [26]. Daily OCx MODIS data with $1 \mathrm{~km}$ resolution from January 2012 to January 2016 were also obtained from website https://oceancolor.gsfc. nasa.gov/cgi/. Each OCx data file contained derived Chl-a (Chlorophyll-a) and ten remote sensing Reflectance in different wave lengths (i.e. $\operatorname{Rrs}_{412}$, $\operatorname{Rrs}_{443}, \operatorname{Rrs}_{466}, \operatorname{Rrs}_{488}, \operatorname{Rrs}_{531}, \operatorname{Rrs}_{547}, \operatorname{Rrs}_{555}, \operatorname{Rrs}_{645}$, $\operatorname{Rrs}_{667}$, and $\left.\operatorname{Rrs}_{678}\right)$. The chlorophyll-a images were processed using the MODIS chlorophyll band ratio algorithm standard OCx [27] merged with the CI
(Color Index) of Hu's algorithm [28]. From the daily OC MODIS data that were downloaded (as presented in the previous paragraph), remote sensing reflectance at a wavelength of $667 \mathrm{~nm}\left(\operatorname{Rrs}_{667}\right)$ data were extracted. Monthly averages of $\operatorname{Rrs}_{667}$ images were used to calculate TSS (Total Suspended Solid) images $\left(\mathrm{g} / \mathrm{m}^{3}\right)$ following Nechad's algorithm [29] and were described by the Eq. (1):

$$
T S S=\frac{601.79 \cdot \operatorname{Rrs}_{667}}{\left(1-\left(1.007 \cdot \operatorname{RrS}_{667}\right)\right)}
$$

All images were combined to generate monthly composite maps, which were then used to generate average values of monthly SST, Chl-a and TSS. Finally, this image was reclassified according to a suitability score of SST, Chl-a and TSS, respectively.

Oceanic data from the Western SCS were downloaded from HYCOM (Hybrid Coordinate Ocean Model) plus the NCODA (Navy Coupled Ocean Data Assimilation) from the US Navy website https://www.hycom.org/data/glbv0pt08 with a spatial resolution of $1 / 12^{\circ}$ (about $10 \mathrm{~km}$ ). A reanalysis data system of HYCOM-NCODA is coupled with local hydrodynamic FEM (Finite Element Model) for extracting sea water salinity and ocean circulation (i.e water current) in coastal waters of Central region of Viet Nam in more detail meshes (i.e. spatial resolution of $1 \mathrm{~km}$ in coastal waters). Then, these mesh data were rasterized into grids of $1 \mathrm{~km}$ and reclassified according to suitability scores of sea water salinity and oceanic current (including velocity and their direction).

Hydrographic charts $(1 / 100,000)$ in coastal waters of Central region of Vietnam from the survey maps of the Map Surveying Department of Vietnam Navy (archived in the library of the Institute of Oceanography) were screen digitized from scanned maps (in hard copy format) to become GIS maps and then they were rasterized and re-sampled into the same size and dimension $(1,000 * 1,000 \mathrm{~m})$.

Social-infrastructural and constraint data (including waste water sources, sewages, industry zones, human 
settlement (urban) and MPAs (Marine Protection Areas) were extracted from the Google Earth Engine. On-screen digitizing was the technique chosen to produce social-infrastructural features as well as constraint data. The final step was to run distance analysis (using buffer function) to measure distances from each data source (social-infrastructural constraint) and reclassify them according to suitability scores.

\subsection{Methodology of GIS Based MCE for Suitable Optimum Site Selection in Oyster Cultivation}

The information overlaid and analyzed for selecting suitable oyster farming areas was based on the MCE technique known as the weighted linear combination [3] and performed through the Eq. (2):

$$
S=\sum_{i}^{n}\left(W_{i} X_{i}\right) \cdot \Pi C j
$$

where:

$S$ : Suitable index for zoning and selection of the best appropriate sites.

$X_{i}$ : Suitable score of factor i. $X_{i}$ appears as a suitable or unsuitable level of environmental factors related to culture object (i.e. Pacific oyster $C$. gigas). Each factor will be reclassified according to suitable/unsuitable tolerances of environmental factors.

$W_{i}$ : Weighting of factor $i$ (with $\sum W_{i}=1$ ). $W_{i}$ appears important level of factor $i$ in comparison with other factors. $W_{i}$ will be determined through pair comparison matrix of factor $i$ in comparison with remaining ones. This matrix is called as Saaty's one [30]. Saaty matrix allows decoding the importance from one (1) to nine (9) and determines relative importance of factor $i$ in comparison with factor $j$ (Table 1).

For example, if parameter $i$ is more important than parameter $j$ then it is decoded by a value of 3 . In contrast, parameter $j$ is less important than parameter $i$ then it is decoded by a value of $1 / 3$. The importance of each factor (or weighting $W_{i}$ ) will be estimated based on Saaty matrix by the calculation of eigenvalues.

$C_{i}$ includes both socio-economic constraints and natural ones. The constrains are decoded in binary, boolean format $(0,1)$. "Suitable" is assigned by value of 1 , "unsuitable" is assigned by value of 0 . The socio-economic constraints included the core area of MPA, premier regions needed for protection, the economic development zone that is unsuited for oyster farm, developed region related to regulation, strategy for local economic development... as well as natural constraints (seed grounds, rocky beds, regions with unsuitable depth, unsuitable substratum for oyster farming) $\left(C_{j}=C_{n} C_{n+1} C_{n+2 .} C_{m}\right)$.

The site selection of oyster farming by MCE, include determining suitable score $X_{i}$, assessing the weighting $W_{i}$ (or important level) and constraint analysis. The block schema for determined suitable area for $C$. gigas farming utilized GIS based MCE techniques (Fig. 2).

Finally, the overlaying GIS maps (with component products of $X_{i}, W_{i}, C_{\mathrm{j}}$ ) and calculation by formula $S=$ $\sum_{i}^{n}\left(W_{i} X_{i}\right) \cdot \prod C_{j}$ will give us zoning maps with suitable areas in different levels.

\section{Results and Discussion}

3.1 Determination of Suitable Score $X i$ of Environmental Parameters for Pacific Oyster (C. gigas) Farming

3.1.1 Suitable Score $X_{i}$ of Water Temperature Factor in the Relationship with Pacific Oyster Cultivation

Sea water temperature has a major effect on the seasonal growth of bivalves and may have strong

Table 1 Comparison pairwise matrix-Saaty matrix determines the importance (weighting) of each other's factors.

\begin{tabular}{llll}
\hline Value & Convention & Value & \\
\hline 1 & Same importance & 2 & Slightly more important \\
3 & Slightly to moderately more important & 4 & Moderately more important \\
5 & Moderately to strongly more important & 6 & Strongly more important \\
7 & Greatly more important & 8 & More greatly important \\
9 & Most absolutely important & & \\
\hline
\end{tabular}




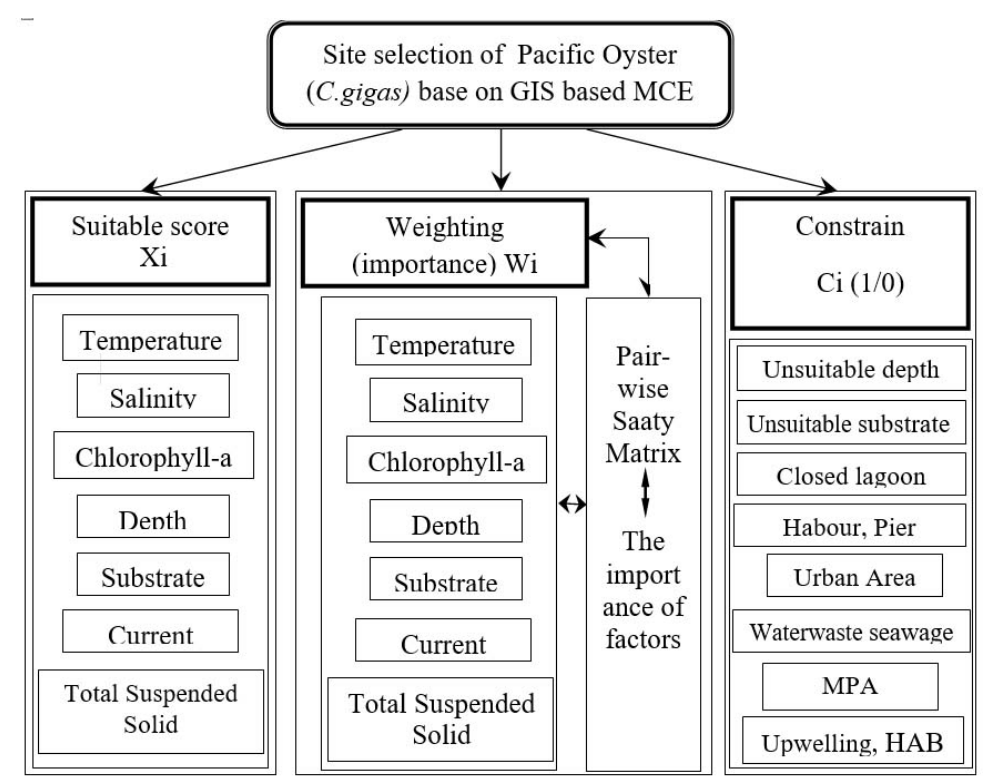

Fig. 2 Flow chart for determined suitable areas for oyster farming by GIS based MCE techniques.

Table 2 Suitable score $\left(X_{i}\right)$ for site selection of Pacific oyster aquaculture relative to water temperature.

\begin{tabular}{llllllllll}
\hline Temperature $\left({ }^{\circ} \mathrm{C}\right)$ & $<14$ & $14-16$ & $16-18$ & $18-20$ & $20-24$ & $24-28$ & $28-31$ & $31-33$ & $>33$ \\
\hline$X_{i}$ & 1 & $1-4$ & $4-6$ & $6-8$ & 8 & $6-8$ & $4-6$ & $1-4$ & 1 \\
\hline
\end{tabular}

$X_{i}=1$ according to less unsuitable level, $X_{i}=8$ according to most suitable level and the suitable level increasing gradually from 1 to 8 .

influence on growth between different cultivation sites [31]. Water temperature is a factor affecting the ability of assimilation of the bivalve filter feeders as oyster [32] and development intensity of oyster will decline sharply when the water temperature reduces to very low levels. Pacific oyster larvae can tolerate temperatures between 15 and $34{ }^{\circ} \mathrm{C}$ [25]. From experimental results in the laboratory, many authors showed that oyster larvae appear to grow most rapidly at a temperature range from 28 to $30^{\circ} \mathrm{C}$ and a salinity range from $19 \%$ to $30 \%$ [33-35]. However, in the natural environment larval development takes place with a water temperature between 16 and $23{ }^{\circ} \mathrm{C}$ and a salinity between $18 \%$ and 35\%. Leda Handog's synthesis results [36] have shown for the Pacific oyster, suitable temperature range is $15-30{ }^{\circ} \mathrm{C}$, optimal condition for the development of the egg is $23-25^{\circ} \mathrm{C}$, suitable condition for reproduction is $25^{\circ} \mathrm{C}$ or greater. Meanwhile, the temperature range suitable for Pacific oyster is $15-25^{\circ} \mathrm{C}$.

Through the synthesis of above-mentioned overviews, we determined suitable temperature tolerance for Pacific oyster as follows: optimum water temperature range: $20-24{ }^{\circ} \mathrm{C}$; suitable temperature ranges of $15-20{ }^{\circ} \mathrm{C}$ and $24-30{ }^{\circ} \mathrm{C}$; suitable temperature ranges lie out of above range (i.e. less than $15{ }^{\circ} \mathrm{C}$ or more than $30{ }^{\circ} \mathrm{C}$ ). From suitable temperature tolerances of $C$. gigas as mentioned above, we reclassified ranking and assigned suitable temperature score $X_{i}$ for $C$. gigas (with 1 being less unsuitable level and 8 being absolutely most suitable) and the detail is shown in Table 2 .

3.1.2 Suitable Score $X_{i}$ of Sea Water Salinity in the Relationship with Pacific Oyster Cultivation

Salinity also has strong influence on the different phases of the life cycle of the bivalve and also oysters (i.e. gametogenesis, fertility, larvae development, and settlement) [25]. Oysters can reproduce and grow in the salinity range of $10 \%-42 \%$ with an optimum range for fertilization being 23\%-36\%o [24]. Optimal salinity for juveniles is similar to mature individuals [37]. Pacific oyster larvae appear to grow most rapidly under experimental conditions at a salinity from 19\%o to $30 \%$ [33-35]. Other authors showed that the 
Table 3 Suitable score $\left(X_{i}\right)$ for site selection of Pacific oyster aquaculture relative to water salinity.

\begin{tabular}{llllllllll}
\hline Salinity (\%) & $<10$ & $10-12$ & $12-16$ & $16-20$ & $20-30$ & $30-31$ & $31-33$ & $33-35$ & $>35$ \\
\hline$X_{i}$ & 1 & $1-4$ & $4-6$ & $6-8$ & 8 & $6-8$ & $4-5$ & $1-4$ & 1 \\
\hline
\end{tabular}

optimum salinity range for the growth of young $C$. gigas is $15 \%$ - $30 \%$, although they could survive even in a wider range of salinity. During the development stage of $C$. gigas oyster juveniles and adults, optimum salinity range is $15 \% 0-30 \%$, whereas the mature $C$. gigas optimum salinity range is $20 \%$ - $30 \%$ [36].

Through the synthesis of overviews on the relationship between salinity factor and oyster growth, we determined the suitable salinity tolerance for Pacific oyster as follows: optimum water salinity range: $20 \%$-30\%o; suitable salinity ranges of $10 \%$ - $20 \%$ and 24\%o-30\%; suitable salinity ranges lie out of above range (i.e. less than $10 \%$ or more than $34 \%$ ). From suitable salinity tolerances of $C$. gigas as above mention, we reclassified ranking and assigned suitable salinity score $X_{i}$ for $C$. gigas (with 1 being less unsuitable level and 8 being absolutely most suitable) and the detail is shown in Table 3.

3.1.3 Suitable Score $\mathrm{X}_{\mathrm{i}}$ of Chl-a Factor in the Relationship with Pacific Oyster Cultivation

Adult oysters are fixed to a hard substrate and therefore the food availability depends entirely on the natural food present in the surrounding waters. Food availability in the surrounding waters is also one of most important factors for optimum site selection of oyster farming (ranked behind salinity and water temperature). Like the vast majority of bivalves, $C$. gigas are filter-feeders using their gills to remove suspended particles from the water. Their food consists of phytoplankton (diatoms and dinoflagellates), copepod larvae, protozoans and detritus, phytoplankton also accounts for a significant proportion of food [24].

Generally, the existence of microalgae does not affect the culture process, but the problem only becomes necessary when considering the limited food resources [36]. Nutrition is considered the factor that most explains variance in larval growth [35]. In estuaries, where the hydrographic conditions are favorable, plankton is abundant and therefore the oysters tend to perform well. During the dry season, the seawater salinity and temperature tend to increase, and the oysters are found to be thin and watery, suggesting a low supply of food [36]. For optimum site selection of bivalve culture, the parameter of Chl-a concentration can be chosen instead of food availability. In practice, Chl-a concentration of $0.5 \mathrm{mg} / \mathrm{m}^{3}$ is considered inadequate for site selection of C. gigas [38]. According to Barillari, et al. [39], the range of Chl-a of between $2-11 \mathrm{mg} / \mathrm{m}^{3}$ is considered as optimal conditions for oyster farming. In local condition of coastal waters of Central Vietnam, the value $10 \mathrm{mg} / \mathrm{L}$ of chl-a content (when eutrophication phenomena can occur) is considered as upper limitation for optimum site selection of $C$. gigas farming.

Through the synthesis of overviews on relationship of Chl-a factor with oyster growth, authors determined suitable tolerance of Chl-a content for Pacific oyster as follows: optimum range of Chl-a content: 2-6 $\mathrm{mg} / \mathrm{m}^{3}$; suitable Chl-a ranges of $0.5-2 \mathrm{mg} / \mathrm{m}^{3}$ and $6-10$ $\mathrm{mg} / \mathrm{m}^{3}$; suitable Chl-a ranges lie out of above range (i.e. less than 0.5 or more than $10 \mathrm{mg} / \mathrm{m}^{3}$ ). From suitable Chl-a tolerances of $C$. gigas as mentioned above, authors reclassified ranking and assigned suitable Chl-a score $X_{i}$ for $C$. gigas (with 1 being less unsuitable level and 8 being absolutely most suitable) with detail as shown in Table 4.

3.1.4 Suitable Score $X_{i}$ of Suspended Matter Factor in the Relationship with Pacific Oyster Cultivation

In the above-mentioned analyses, $C$. gigas can capture a high variety of particles from the water such as bacteria, protozoa, microalgae, invertebrate larvae and detritus [23]. The organic components in the suspended material can be assimilated and used as feed for oysters, but this food source accounts for an insignificant percentage [24]. On the other hand, unsuitable areas of oyster farming such as the muddy 
Table 4 Suitable score $\left(X_{i}\right)$ for site selection of Pacific oyster aquaculture relative to Chl-a content.

\begin{tabular}{llllllllll}
\hline Chl-a $\left(\mathrm{mg} / \mathrm{m}^{3}\right)$ & $<0.5$ & $0.5-0.8$ & $0.8-1.0$ & $1.0-2.0$ & $2.0-6.0$ & $6.0-7.0$ & $7.0-8.0$ & $8.0-10.0$ & $>10.0$ \\
\hline$X_{i}$ & 1 & $1-4$ & $4-6$ & $6-8$ & 8 & $6-8$ & $4-6$ & $1-4$ & 1 \\
\hline
\end{tabular}

Table 5 TSS (mg/L) in some lagoons in Central Vietnam.

\begin{tabular}{lllllll}
\hline & \multicolumn{3}{c}{ Rainy season } & \multicolumn{3}{c}{ Dry season } \\
\cline { 2 - 7 } & Average & Max & Min & Average & Max & Min \\
\hline De gi lagoon & 18.54 & 75.1 & 2.32 & 9.72 & 24.2 & 1.75 \\
Thi nai lagoon & 23.43 & 156.0 & 1.55 & 13.28 & 66.20 & 2.70 \\
Nha Phu lagoon & 47.62 & 52.9 & 42.4 & 24.5 & 27.9 & 21.0 \\
Nai lagoon & 24.4 & 82.1 & 6.7 & 17.7 & 29.3 & 1.6 \\
\hline
\end{tabular}

Source: Pham and Le [42].

Table 6 Suitable score $\left(X_{i}\right)$ for site selection of Pacific oyster aquaculture relative to TSS concentration.

\begin{tabular}{llllllllll}
\hline TSS $(\mathrm{mg} / \mathrm{L})$ & $<0.1$ & $0.1-0.5$ & $0.5-0.8$ & $0.8-1.0$ & $1.0-20$ & $20-24$ & $24-30$ & $30-40$ & $>40$ \\
\hline$X_{i}$ & 1 & $1-3$ & $3-6$ & $6-8$ & 8 & $6-8$ & $3-6$ & $1-3$ & 1 \\
\hline
\end{tabular}

seafloor should be eliminated as the impact of sedimentation on organisms impede the respiration process of oyster. In the book-Site Selection and Water Quality in Mariculture, [40], Prema showed that, suspended solids in a suitable site for mariculture should not exceed $2 \mathrm{mg} / \mathrm{L}$. Another study on optimum site selection for Pearl oyster-Pintada fucata, Rahul and his colleagues [41] showed suitable tolerance of each parameter. For TSS, they determined suitable/unsuitable tolerances as follows: (a) high suitable: 10-20 mg/L; (b) suitable: 10-20 mg/L; and (c) unsuitable with TSS $>30 \mathrm{mg} / \mathrm{L}$ [41]. Through the synthesis of survey data from previous projects in Central Vietnam (such as Nha Phu, Thi Nai, De Gi Nai lagoons...). Table 5 shows the spatial variation of total suspended solid in these coastal waters.

Through the synthesis of overviews on relationship of suspended matter factor with oyster growth, we determined suitable tolerance of TSS concentration for Pacific oyster as follows: optimum range of TSS concentration: 1-20 $\mathrm{mg} / \mathrm{L}$; suitable TSS ranges of 20-30 mg/L; suitable TSS concentration ranges lie out of the above range (i.e. less 1 or more $30 \mathrm{mg} / \mathrm{L}$ ). From suitable temperature tolerances of $C$. gigas as mentioned above, authors reclassified ranking and assigned suitable temperature score $X_{i}$ for $C$. gigas (with 1 being less unsuitable level and 8 being absolutely most suitable). See Table 6 for details.

3.1.5 Suitable Score $\mathrm{X}_{\mathrm{i}}$ of Hydrodynamic Factor in the Relationship with Pacific Oyster Cultivation

The hydrodynamic conditions can contribute productivity through food provision and seed diffusion [22], but it can also cause disadvantage to oyster farming when current velocity is too high or too low [23]. Bivalve culture sites should not be in the vicinity of strong currents particularly where bottom culture is practiced as strong currents usually generate high turbidity and high siltation rates. However, moderate currents are needed to provide adequate food supply. Currents of $0.02-0.1 \mathrm{~m} / \mathrm{sec}$ have been reported to be suitable for cockle cultures, while stronger currents are usually required for the hanging method due to the intensive culture nature of this method [43]. In the hanging method, slow water movement usually results in slow growth of the bivalves due to the poor replenishment of food. Slow currents also promote the settling of organic and inorganic particulate materials on the cultured organisms. Potential sites should have a current speed within the range of $0.1-0.3 \mathrm{~m} / \mathrm{sec}$. Oysters are filter-feeders and are considered obligatory herbivores. Adult oysters are fixed to a hard substrate and therefore the food availability depends entirely on the natural food present in the surrounding waters. Thus, oysters completely depend on tidal currents for 
obtaining food; low current velocities and limited flushing hamper growth and fattening. Equipment can also be damaged by strong tidal currents. Sheltered areas with tidal flows of $50-100 \mathrm{~cm} / \mathrm{s}$ usually provide the best conditions and will give sufficient water exchange to supply the animals with an adequate supply of food and oxygen and for the removal of wastes [31]. The poor growth of oyster usually occurs where the water flow is not strong enough, partly due to lack of plankton and other food sources, thereby restricting the filter feeding ability of oysters [36]. Some studies have concluded that a low current velocity $(20 \mathrm{~cm} / \mathrm{s})$ or if too large, is not suitable for bivalve filter feeders such as oysters [44, 45].

Through the synthesis of overviews on relationship of factor of sea current velocity with oyster growth, authors determined suitable tolerance of sea water current for Pacific oyster as follows: optimum water current velocity range: $20-30 \mathrm{~cm} / \mathrm{s}$; suitable current velocity ranges of $10-20 \mathrm{~cm} / \mathrm{s}$ and $30-40 \mathrm{~cm} / \mathrm{s}$; suitable salinity ranges lie out of above range (i.e. less $10 \mathrm{~cm} / \mathrm{s}$ or more $40 \mathrm{~cm} / \mathrm{s}$ ). From suitable current velocity tolerances of $C$. gigas as above mention, authors reclassified ranking and assigned suitable temperature score $X_{i}$ for $C$. gigas (with 1 being less unsuitable level and 8 being absolutely most suitable), details shown in Table 7.

3.1.6 Suitable Score $X_{i}$ of the Depth in the Relationship with Pacific Oyster Cultivation

Noting that, oysters and other bivalve filter feeder species only develop well when they lie completely in the water media [31]. Growth intensity of oyster (and bivalve animals) is strongly influenced by exposure time. The experimental results of Laing and Spencer have pointed out the growth of the oysters will stop when the exposure time is greater than $35 \%$ [31]. For that reason, to select the criteria of farming depth, we need to determine the exposure time and tidal amplitude. C. gigas is a bivalve species that develops well in intertidal with suitable depth changing from high/highest level to low/lowest level $[36,46]$. In central Vietnam, tidal amplitude changes from 2.6-2.8 m, suitable depth interval for oyster aquaculture is $2-5 \mathrm{~m}$.

From suitable tolerances of the depth for C. gigas cultivation, authors reclassified ranking and assigned suitable temperature score $X_{i}$ for $C$. gigas (with 1 being less unsuitable level and 8 being absolutely most suitable) with detailsas shown in Table 8 .

\subsection{Assessing the Weighting Wi of Environmental} Parameters for Pacific Oyster (C. gigas) Farming

The weighting $W_{i}$ appears as an important assessible factor in the growth of the Pacific oyster. The weighting $W_{i}$ is the second index determined in the MCE algorithm (see formula 2). In this case, authors analyzed the two main scenarios for calculating the weighting $W_{i}$, as follows, (i) the 1 st scenario of suitable oyster farming sitting in coastal waters; and (ii) the 2 nd scenario of suitable oyster farming sitting in offshore waters.

3.2.1 The Calculation the Weighting $\mathrm{W}_{\mathrm{i}}$ in $1 \mathrm{st}$ Scenario of Oyster Farming in Coastal Waters

In the first scenario, the aquaculture areas of $C$. gigas oyster focused mainly in coastal waters, lagoons and bays using traditional farming techniques (tray, raft, rack, stack...). These culture techniques are applied in Nha Phu laggon (Khanh Hoa province), Thi Nai lagoon, De gi lagoon (Binh Dinh province), Sa Ky, Sa Huynh (Quang Ngai province), Vinh Hy, Dam Nai

Table 7 Suitable score $\left(X_{i}\right)$ for site selection of Pacific oyster aquaculture relative to oceanic current.

\begin{tabular}{llllllllll}
\hline Velocity $(\mathrm{cm} / \mathrm{s})$ & $<10$ & $10-12$ & $12-15$ & $15-20$ & $20-30$ & $30-34$ & $34-40$ & $40-50$ & $>50$ \\
\hline$X_{i}$ & 1 & $1-3$ & $3-6$ & $6-8$ & 8 & $6-8$ & $3-6$ & $1-3$ & 1 \\
\hline
\end{tabular}

Table 8 Suitable score $\left(X_{i}\right)$ for site selection of Pacific oyster aquaculture relevance to factor of the depth of farming site.

\begin{tabular}{lllllllll}
\hline Depth $(\mathrm{m})$ & $<1$ & $1-2$ & $2-4$ & $4-6$ & $6-8$ & $8-10$ & $10-20$ & $>20$ \\
\hline$X_{i}$ & 1 & $6-8$ & 8 & $6-8$ & $4-6$ & $2-4$ & $1-2$ & 1 \\
\hline
\end{tabular}


Table 9 Pair-wise matrix (Saaty matrix) and the weighting for site selection of oyster farming in the first scenario.

\begin{tabular}{llllllll}
\hline & Depth & Temperature & Salinity & chl-a & TSS & $V_{\text {current }}$ & $W_{i}$ \\
\hline Depth & 1 & 3 & 3 & 5 & 7 & 9 & 0.423 \\
Temperature & $1 / 3$ & 1 & 3 & 5 & 7 & 9 & 0.2 \\
Salinity & $1 / 3$ & $1 / 3$ & 1 & 3 & 5 & 7 & 0.2 \\
Chl-a & $1 / 5$ & $1 / 5$ & $1 / 3$ & 1 & 3 & 5 & 0.098 \\
TSS & $1 / 7$ & $1 / 7$ & $1 / 5$ & $1 / 3$ & 1 & 3 & 0.051 \\
$V_{\text {current }}$ & $1 / 9$ & $1 / 9$ & $1 / 7$ & $1 / 5$ & $1 / 3$ & 1 & 0.028 \\
$W_{i}$ & 0.423 & 0.2 & 0.2 & 0.098 & 0.051 & 0.028 & \\
\hline
\end{tabular}

Table 10 Pair-wise matrix (Saaty matrix) on relative importance of natural-environmental factors for site selection of oyster farming in the second scenario.

\begin{tabular}{llllllll}
\hline & Temperature & Salinity & Chl-a & TSS & $V_{\text {current }}$ & Depth & $W_{i}$ \\
\hline Temperature & 1 & 1 & 3 & 5 & 7 & 9 & 0.325 \\
Salinity & 1 & 1 & 3 & 5 & 7 & 9 & 0.325 \\
Chl-a & $1 / 3$ & $1 / 3$ & 1 & 3 & 5 & 7 & 0.194 \\
TSS & $1 / 5$ & $1 / 5$ & $1 / 3$ & 1 & 3 & 5 & 0.086 \\
$V_{\text {current }}$ & $1 / 7$ & $1 / 7$ & $1 / 5$ & $1 / 3$ & 1 & 3 & 0.045 \\
Depth & $1 / 9$ & $1 / 9$ & $1 / 7$ & $1 / 5$ & $1 / 3$ & 1 & 0.025 \\
$W_{i}$ & 0.325 & 0.325 & 0.194 & 0.086 & 0.045 & 0.025 & \\
\hline
\end{tabular}

(Ninh Thuan province), Song Cau andAn Ninh (Phu Yen province)... According to this scenario, the important level of each factor was chosen as follows: The depth is the most importance (level 1) for suitable site selection of oyster farming. SST and SSS (Sea Surface Salinity) have the level 2 importance for suitable farming siting; Chl-a content has level 3 importance for suitable farming siting; TSS concentration receives level 4 importance for suitable farming siting; while sea current factor gets the least importance (level 5). Consequently, MCE by first scenario with the importance of parameters is chosen in order as follow: depth $\rightarrow$ temperature, salinity $\rightarrow$ Chl-a $\rightarrow$ TSS $\rightarrow$ sea current. A pair-wise matrix of relative importance between factor pairs is built in the first scenario and is shown in Table 9. The weighting of each parameter will be obtained from estimating the eigenvalues based on Saaty's matrix and present in the last row/column of Table 9 .

3.2.2 The Calculation the Weighting $\mathrm{W}_{\mathrm{i}}$ in $2 \mathrm{nd}$ Scenario of Suitable Site Selection of Oyster Farming in Open Sea, Offshore Water

In the second scenario, $C$. gigas farming by modern technologies in open sea, offshore waters with long-line string hanging in deeper depths. In fact, currently there are no sites where oyster is cultivated by this technique. However, with application of analysis by MCE technique according to second scenario, beneficial conditions are created to determine potential farming areas that will develop in the near future (if available). Under this scenario the importance of the factor was chosen as follows: according to this scenario, the important level of each factor is chosen in order as follow: temperature, salinity $\rightarrow$ Chl-a $\rightarrow$ TSS $\rightarrow$ sea current $\rightarrow$ depth. A pair-wise matrix on relative importance between factor pairs is built into thesecond scenario and is shown in Table 10. The weighting of each parameter will be obtained from estimating the eigenvalues and present in last row/column of Table 10.

3.2.3 Suitable areas of Oyster Farming obtained from MCE Analysis with Non-constrains

The calculated results of factor score $X_{i}$ and weighting $W_{i}$ as presented as above, based on MCE techniques and environmental parameters and non-constraint analysis, give us seasonal distribution scenes of suitable/un-suitable areas of C. gigas farming. 


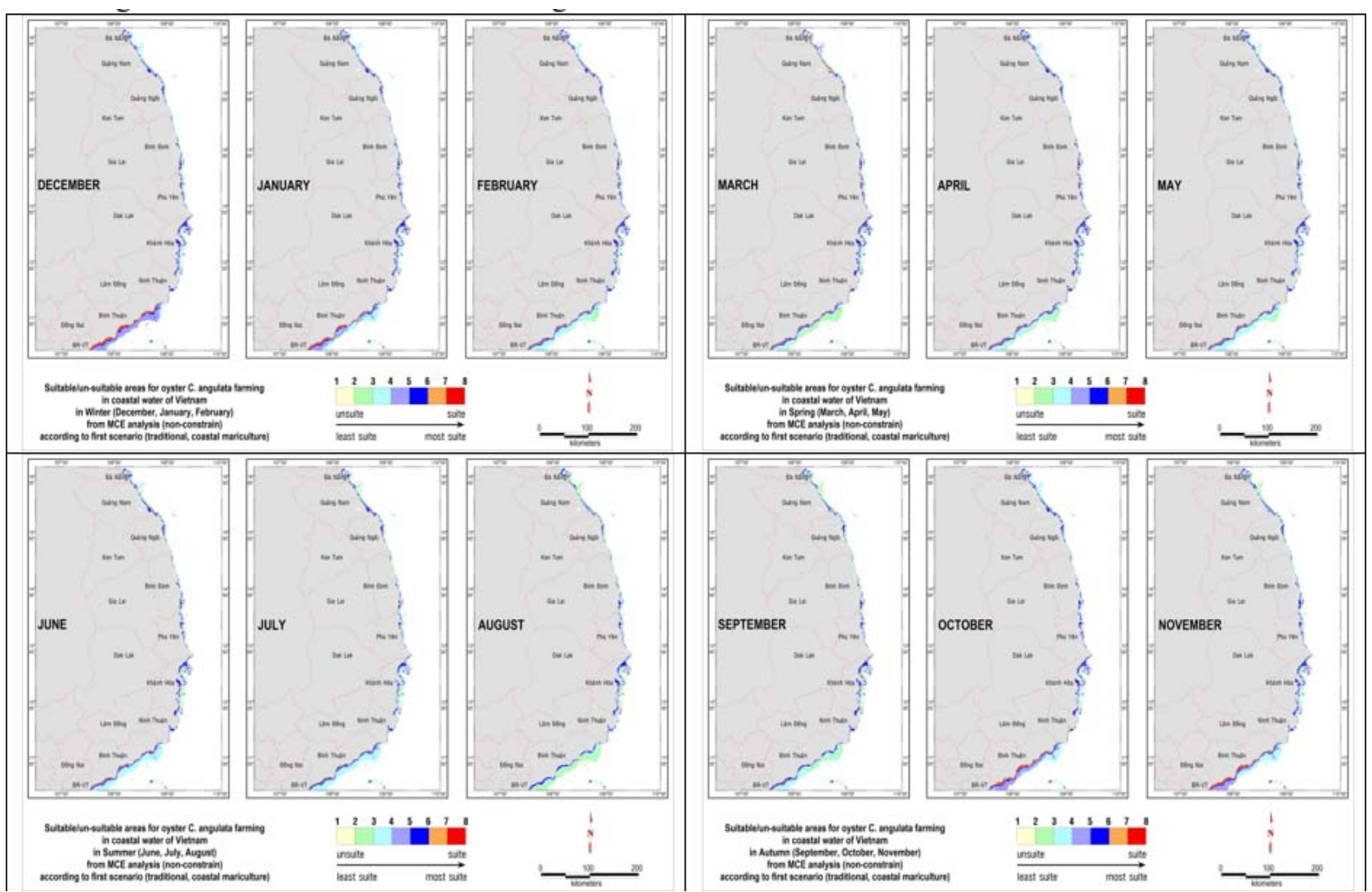

Fig. 3 Suitable/un-suitable areas for Pacific oyster farming in coastal water of Vietnam from MCE analysis (non-constraint) according to first scenario (traditional, coastal mariculture).

Light yellow: least suitable (1), blue light: medium suitable (4); red: most suitable (8).

The distribution maps of suitable/unsuitable areas for oyster farming from MCE (non-constraint) according to first scenario are shown in Fig. 3, and maps of the second scenario are shown in Fig. 4.

Analyzed results from both scenarios shown that in the first scenario, depth is chosen as the most important factor (next parameters are temperature and salinity) in the selection of best appropriate farming sites by MCE (non-constraint) analysis.

Most suitable sites that are obtained from MCE-First scenario (as in mouths of Nha Phu lagoon, Thi Nai lagoon, Xuan Dai bay, and some others) appear permanent consistency and approximately coincide with existing farming areas of Pacific oyster $(C$. gigas) in coastal waters in Central Vietnam.

In the second scenario, depth is chosen as a factor with minor importance (most important parameters are temperature and salinity) in selection of farming sites by MCE (non-constraint) analysis. Most suitable sites that are obtained from MCE-second scenario are not consistent. In some periods of December, January, the best suitable farming sites appear in all coastal waters of the south of project region (i.e. in Binh Thuan province, and few in Phan rang bay), whereas in March, the best suitable sites appear in the north (i.e. in Da Nang and Quang Nam). The best sites in offshore waters almost do not exist in both scenarios. MCE based on parameters in first scenario is better in comparison with the second scenario. So, MCE by first scenario with parameter dataset is chosen for final MCE analysis with constraints. The order on the importance of parameters (from high level to low one) was chosen as follows: depth $\rightarrow$ temperature, salinity $\rightarrow$ Chl-a $\rightarrow$ TSS $\rightarrow$ sea current. 


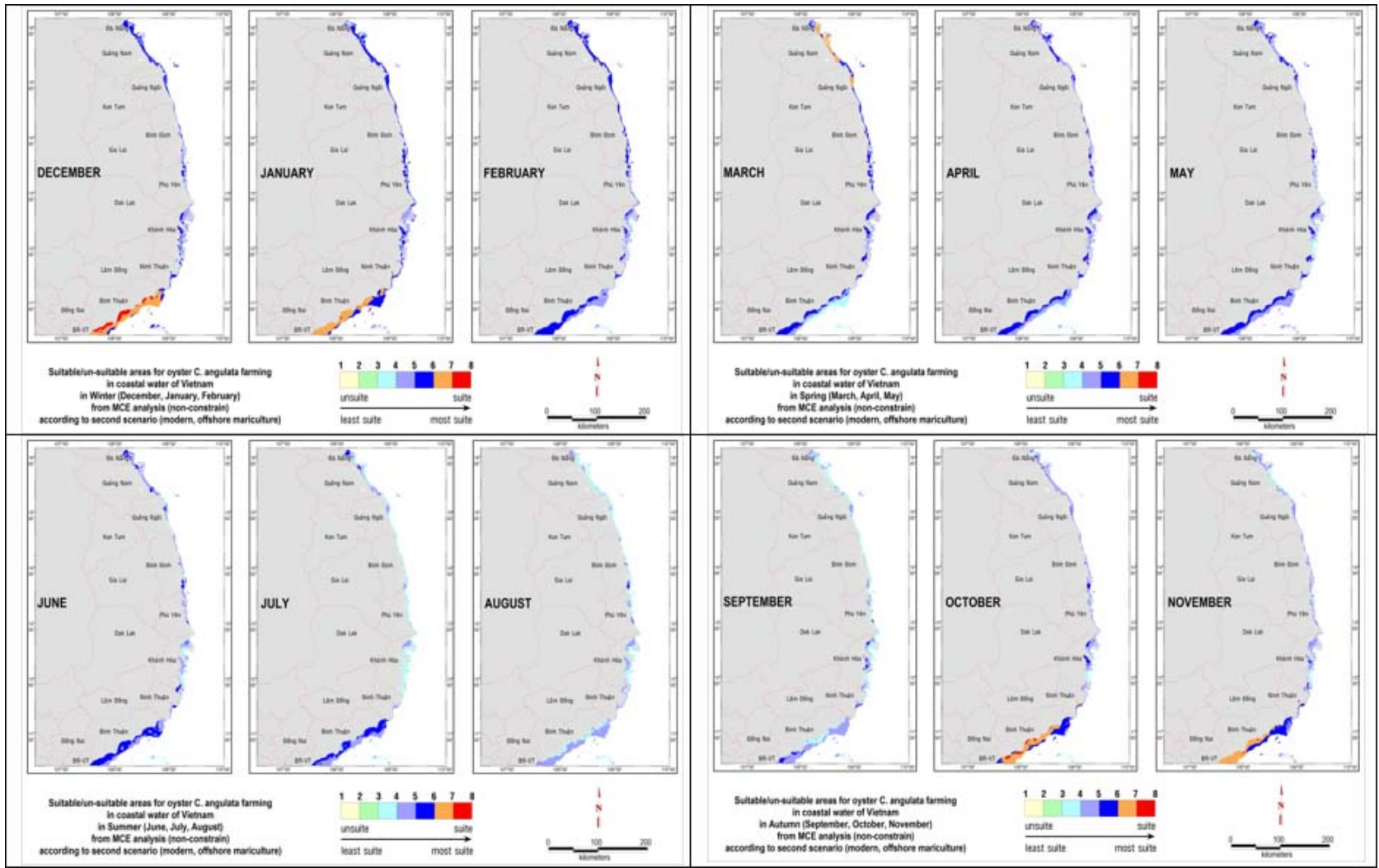

Fig. 4 Suitable/un-suitable areas for Pacific oyster farming in coastal water of Vietnam from MCE analysis (non-constraint) according to second scenario (modern, offshore mariculture).

Light yellow: least suitable (1), blue light: medium suitable (4); red: most suitable (8).

\subsection{Constraint Analysis of Environmental and} Socio-Economic Categories in Optimum Site Section of Pacific Oyster Farming by MCE Technique

In MCE technique, constrain factors (including both environmental parameters and socio-economic subjects) will be decoded in Boolean (binary) format (i.e., values of 0 and 1). Suitable waters will be assigned by value of unit (i.e.: 1), whereas unsuitable ones will be assigned by value zero (i.e.: 0).

\subsubsection{The Depth in Constraint Analysis}

In terms of the ecological aspect, Pacific oysters are bivalve, filter feeder species that live in intertidal zones where the depth changes from high higher level to low lower one [36, 46]. In coastal waters of Central Vietnam, where tidal amplitude changes from 2.6-2.8 $\mathrm{m}$, the best suitable depth interval for $C$. gigas farming will be $2-5 \mathrm{~m}$. However, because of new modern aquaculture technique in future, oyster can adapt to some deeper waters, the suitable depth can be extended, $\mathrm{C}_{\text {depth }}=0$ with the depth more $20 \mathrm{~m}$ deep and $\mathrm{C}_{\text {depth }}=1$ with the depth is less $20 \mathrm{~m}$ deep.

3.3.2 The Substratum and Shore Line Types in Constraint Analysis

Oysters are cultured on the beds requiring a sediment sufficiently firm to prevent them from sinking and being smothered [31]. The substrate types of mud seafloor usually exist in areas where the water circulation is not good and unsuitable for oyster farming. These waters are assigned $\mathrm{C}_{\text {substrate }}=0$. The bed rock, rocky cliffs in Central Vietnam usually are steep, prone to the impact of strong waves, and too narrow for farming, reducing their suitability for oyster farms. In the coastal waters that lie close to sandy eolian dunes, these areas are not sheltered well by wave impact (usually across sandy grounds), are covered by coarse sand material; while clean water and necessary food sources such as phytoplankton are 
limited. These regions are almost always not suitable for oyster farming. These waters are assigned $\mathrm{C}_{\text {substrate }}$ $=0$. Outside of these waters, they are assigned by $\mathrm{C}_{\text {substrate }}=1$. In the closed water bodies, there is insufficient water exchange between the sea and inside lagoons. These waters are usually fresh, with low salinity and low water exchange and are covered by muddy, silty materials. They generally are not suitable for oyster farming. These waters are assigned $\mathrm{C}_{\text {substrate }}=0$. Outside these sites, they are assigned by $\mathrm{C}_{\text {substrate }}=1$. Areas near the river mouths are also not suitable for oyster farming. They were considered also as constraint (score 0 ). These waters are also assigned $\mathrm{C}_{\text {NearRiver }}=0$.

3.3.3 Potential Regions Prone to Strong Impact of Natural Disasters and Environmental Risks

Upwelling phenomena in summer in coastal water of Ninh Thuan-Binh Thuan created algae bloom as well as HAB (Harmful Algae Bloom) and resulted in the risks of the oxygen content depletion. The filter feeder products with HAB infection in internal organs of oyster will contain Paralytic shellfish poisoning (PSP), Neurotoxic Shellfish Poisoning (NSP), Amnesic shellfish poisoning (ASP), Diarrhetic Shellfish Poisoning (DSP) toxins and affect human health (if ingested). These water regions must be rejected as sites for aquaculture. They are assigned with $\mathrm{C}_{\mathrm{HAB}}=0$. The oyster cages in coastal waters where they are not sheltered well by strong wave (mainly NorthEast wind) impact are often easily damaged. They are assigned with $\mathrm{C}_{\text {Disaster }}=0$.

3.3.4 High Bio-Productivity Underwater Habitats and MPAs

In coastal waters where coral reefs, seagrass beds and seaweed meadows exist.... these provide high bio-productivity and are abundant food of plankton. These regions are highly suitable for oyster farming. However, some of them are areas that need to be protected for conservation purpose as MPAs and need to be avoided for oyster farming. Core areas of MPA are assigned by $\mathrm{C}_{\mathrm{MPA}}=0$.

\subsubsection{Human Facilities in Constraint Analysis}

Based on analyzed results in previous sections, the phenomena of oxygen content depletion is one of the main reasons causing mass mortality or reducing the yield of mariculture products (including oyster farming). Phenomena such as "black water zones" in coastal water lie in close relationship to sewage, WWTPs (Water Waste Treatment Plans), fishery markets, harbors, industrial zones and black water channels where water runs directly to sea under influence of domestic, aquaculture, agriculture activities, and they are potential regions of oxygen content depletion. These constraint layers limit the site suitability for oyster culture. Fishery markets, harbors and areas near the township and industrial were considered with a constraint score of 0 . The areas that lie out of distance of $2 \mathrm{~km}$ from pollution sources will be assigned by a score of 1 .

\subsection{Suitable Sites for Oyster Farming in Coastal Regions in Central of Vietnam from MCE Analysis}

Based on the dataset of factor score $X_{i}$ and weighting $W_{i}$, and factor constraint $\mathrm{C}_{\mathrm{j}}$, the monthly map set of suitable sites for oyster farming in Central Vietnam is obtained from MCE method. Detail results are shown in Fig. 5.

From MCE technology (with constraint analysis) we are allowed to select some of the best sites for Pacific oyster farming where high suitability scores were obtained ( $\mathrm{S}_{\mathrm{i}}$ from 7 to 8 ). Those are: South of Son Tra peninsula (Da Nang), In An Hoa embayment, Nui Thanh district (Quang Nam province), Sa Ky (Binh Son district) and Sa Huynh (Duc Pho district) Quang Ngai province, Mouth of Thi Nai lagoon and coastal water of Quy Nhon bay (Binh Dinh province), Mouth of $\mathrm{Cu}$ Mong lagoon and mouth of Xuan Dai bay (Phu Yen Province), The West of Ben Goi Bay (Van Ninh district), mouth of Nha Phu lagoon (Ninh Hoa district, Khanh Hoa province, North of Phan Rang bay (Ninh Thuan province) (Fig. 6). These areas were shown to have 
the optimum condition for oyster culture in coastal waters of Central Vietnam. As expected, most of suitable sites which were found from MCE analysis, relatively coincide with existing farming areas of Pacific oyster (C. gigas) in this region. This is because most of the parameters (biophysical and social-infrastructural) in the study area are favorable for oyster culture development. Moreover, some new suitable sites for oyster culture in this region also were found.

The most appropriate areas for Pacific oyster farming lie in orange/red patterns patches

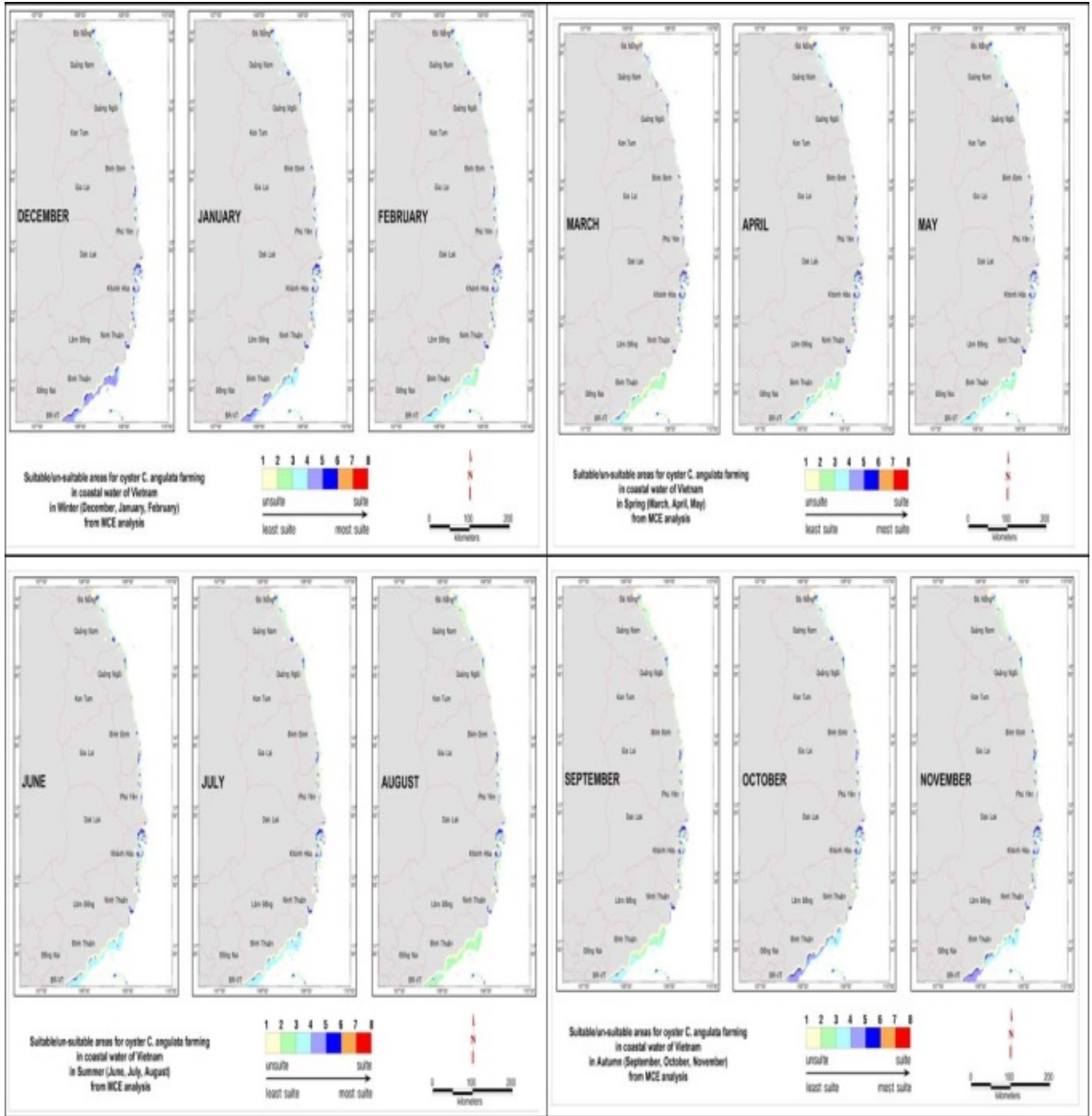

Fig. 5 Suitable/un-suitable areas for Pacific oyster farming in coastal waters of Vietnam from MCE analysis with constrains.

Light yellow: least suitable, blue light: medium suitable; red: most suitable.

The suitable level increases gradually from value of 1 (least suitable) to value of 8 (most suitable). 
GIS-Based Multi-Criteria Evaluation Models for Selection of Suitable Sites for Pacific Oyster

(Crassostrea gigas) Aquaculture in the Central Region of Vietnam

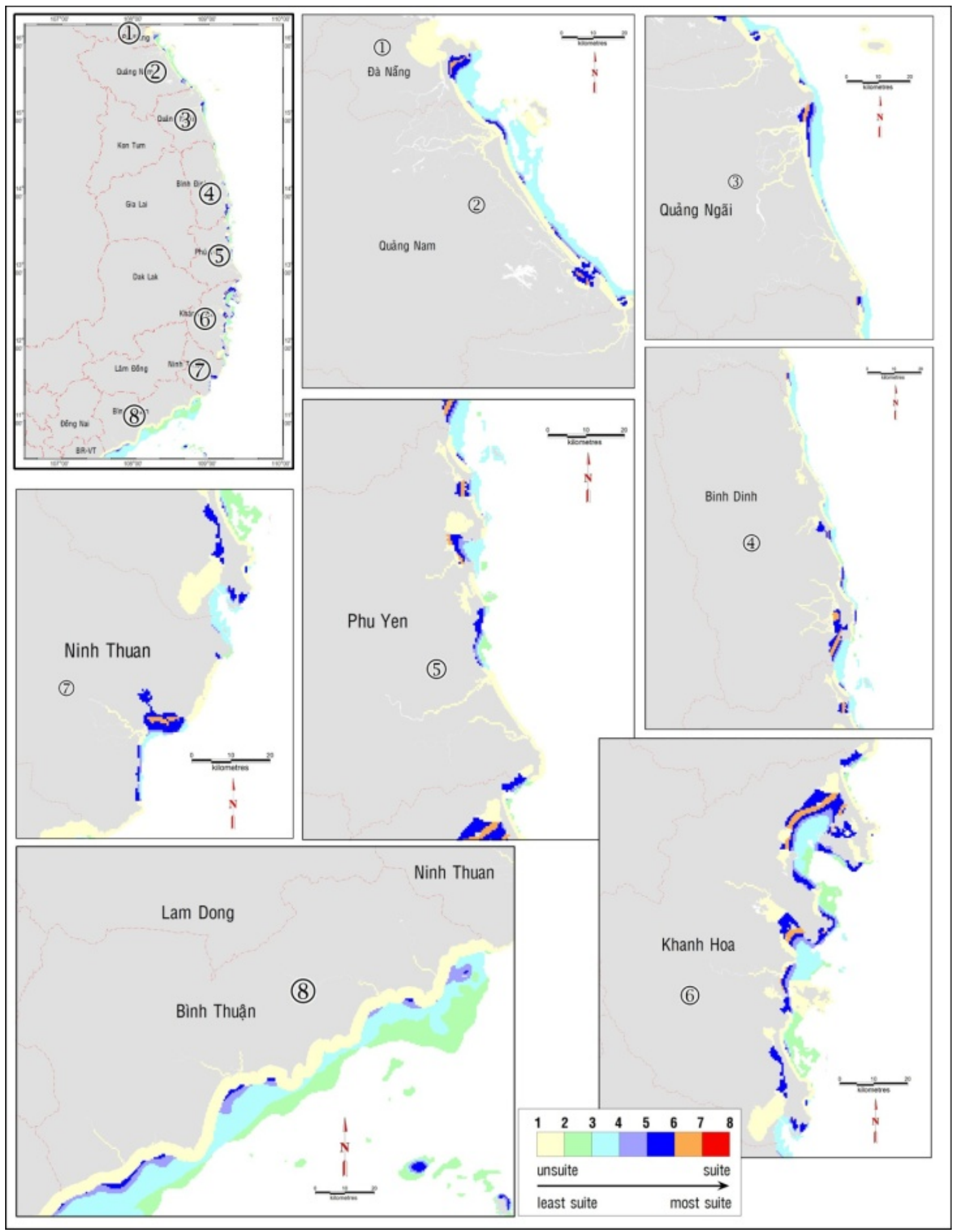

Fig. 6 Detail results of site selection Pacific oyster farming from MCE method. 


\section{Conclusion}

This study demonstrated the use of GIS based MCE model for suitable site selection for oyster culture in coastal waters in Central regions of Vietnam based on certain important criteria and showed acceptable results. From MCE methodology (with constraint analysis), authors are allowed to select some of the best sites for Pacific oyster farming where high suitability scores are obtained. As expected, most of the suitable sites which are found from MCE analysis, relatively coincide with existing farming areas of Pacific oyster (C. gigas) in this region. This is because, most of the parameters (biophysical and social-infrastructural) in the study area are favorable for oyster culture development. Moreover, some new suitable sites for oyster culture in this region also were found. The processed results also show that it works effectively to establish spatial models for identifying the most suitable areas for hanging culture of Pacific oyster development. This study also shows that with appropriate information (including $\mathrm{OCx}$ remote sensing data, Google Earth Engine, Reanalysis-Assimilation modeling in oceanic data, GIS based models...) will be powerful tools for site selection decision making. As more data become available either from satellite images or field measurements, the usefulness of this tool will increase and provide a range of functions embedded in various components that can be tailored for suitable site selection.

\section{Funding}

This research was funded by Vietnam Academy of Science and Technology through the project "Application of Remote sensing and GIS technologies for Management, Environmental Monitoring and Early Warning of Diseases in Aquaculture" (the grant number is VT-UD.07/17-20), which belongs to the National Program on Space Science and Technology (2016-2020).

\section{References}

[1] FAO (Food and Agriculture Organization of the United Nations). 2009. "State of World Aquaculture 2008." FAO Fisheries and Aquaculture Department. http://www.fao.org/docrep/011/i0250e/i0250e00.html.

[2] Griffin, M. 2013. "Geographic Information Systems and Remote Sensing, Applications in Shellfish Aquaculture and Oyster Restoration.” NRS 509.

[3] Malczewski, J. 2000. "On the Use of Weighted Linear Combination Method in GIS: Common and Best Practice Approach." Transactions in GIS 4 (1): 5.

[4] Kapetsky, J. M., and Aguilar-Manjarrez, J. 2010. "Geographic Information Systems, Remote Sensing and Mapping for the Development and Management of Marine Aquaculture." In the State of World Fisheries and Aquaculture, 150-4.

[5] GESAMP (IMO/FAO/UNESCO/WMO/WHO/IAEA/UN /UNEP) Joint Group of Experts on the Scientific Aspects of Marine Pollution. 2001. Planning and Management for Sustainable Coastal Aquaculture Development. GESAMP Report Studies.

[6] Perez-Sanchez, E., and Muir, J. R. 2003. "Fishermen Perception on Resources Management and Aquaculture Development in the Mecoacan Estuary, Tabasco, Mexico.” Ocean and Coastal Management 46: 681-700. doi: 10.1016/S0964-5691(03)00041-3.

[7] Buitrago, J., Rada, M., Hernandez, H., and Buitrago, E. 2005. "A Single-Use Site Selection Technique, Using GIS, for Aquaculture Planning: Choosing Locations for Mangrove Oyster Raft Culture in Margarita Island, Venezuela." Environ Manage 35: 544-56. doi: 10.1007/s00267-004-0087-9.

[8] Radiarta, I. N., Saitoh, S., and Miyazono, A. 2008. "GIS-Based Multi-criteria Evaluation Models for Identifying Suitable Sites for Japanese Scallop (Mizuhopecten yessoensis) Aquaculture in Funka Bay, Southwestern Hokkaido, Japan." Aquaculture 284: 127-35. doi:10.1016/j.aquaculture.2008.07.048.

[9] Soto, D., Aguilar-Manjarrez, J., and Hishamunda, N., eds. 2008. Building an Ecosystem Approach to Aquaculture. FAO/Universitat de les Illes Balears Expert Workshop, 7-11 May 2007, Palma de Mallorca, Spain.

[10] Longdill, P. C., Healy, T. R., and Black, K. P. 2008. "GIS-Based Models for Sustainable Open-Coast Shellfish Aquaculture Management Area Site Selection." Ocean and Coastal Management 51: 612-24.

[11] Meaden, G. J. 2009. "Geographical Information Systems (GIS) in Fisheries Management and Research." In Computers in Fisheries Research, 2nd ed., edited by B. A. Megrey and E. Moksness. Dordrecht, Netherlands: Springer Science, 93-120. 
[12] Silva, C., Ferreira, J. G., Bricker, S. B., DelValls, T. A., Martín-Díaz, M. L., and Yáñez, E. 2011. "Site Selection for Shellfish Aquaculture by Means of GIS and Farm-Scale Models, with an Emphasis on Data-Poor Environments." $\quad$ Aquaculture 444-57.doi:10.1016/j.aquaculture.2011.05.033.

[13] Silva, C., Barbieri, M. A., Yáñez, E., Gutiérrez-Estrad, J. C., and DelVall, T. A. 2012. "Using Indicators and Models for an Ecosystem Approach to Fisheries and Aquaculture Management: The Anchovy Fishery and Pacific Oyster Culture in Chile: Case Studies." Latin American Journal of Aquctic Research 40 (4): 955-69. doi: 10.3856/vol40-issue4-fulltext-12.

[14] Wyrtki, K. 1961. Scientific Results of Marine Investigations of the South China Sea and the Gulf of Thailand 1959-1961. Naga Report Vol. 2. San Diego, University of California, 169.

[15] Fang, G., Fang, W., Fang, Y., and Wang, K. 1998. "A Survey of Studies on the South China Sea Upper Ocean Circulation." Acta Oceanographica Taiwanica 37 (1): 1-16.

[16] Chu, P. C., Edmons, N. L., and Fan, C. 1999. "Dynamical Mechanisms for the South China Sea Seasonal Circulation and Thermohaline Variabilities." Journal of Physical Oceanography $29 \quad$ (11): 2971-89. doi:10.1175/1520-0485(1999)029<2971:DMFTSC $>2.0$.C $\mathrm{O} ; 2$.

[17] Dippner, J. W., Nguyen, K. V., Hein, H., Ohde, T., and Loick, N. 2007. "Monsoon Induced Upwelling off the Vietnamese Coast." Ocean Dynamics 57 (1): 46-62. doi: 10.1007/s10236-006-0091-0.

[18] Shaw, P.-T., Chao, S.-Y., Liu, K.-K., Pai, S.-C., and Liu, C.-T. 1996. "Winter Upwelling off Luzon in the Northeastern South China Sea." Journal of Geophysical Research 101 (C7): 16435-48. doi: 10.1029/96JC01064.

[19] Chao, S.-Y., Shaw, P.-T., and Wu, S. Y. 1996. "Deep Water Ventilation in the South China Sea." Deep Sea Research Part I: Oceanographic Research Papers 43 (4): 445-66. doi: 10.1016/0967-0637(96)00025-8.

[20] Liu, K.-K., Chao, S.-Y., Shaw, P. T., Gong, G.-C., Chen, C.-C., and Tang, T. Y. 2002. "Monsoon-Forced Chlorophyll Distribution and Primary Production in the South China Sea: Observations and a Numerical Study." Deep Sea Research Part I: Oceanographic Research $\begin{array}{llll}\text { Papers } & 49 & \text { (8): } & 1387-412 .\end{array}$ 10.1016/S0967-0637(02)00035-3.

[21] Brown, J. R. 1988. "Multivariate Analyses of the Role of Environmental Factors in Seasonal and Site-Related Growth Variation in the Pacific Oyster, Crassostrea gigas." Marine Ecology Progress Series 45 (3): 225-36. doi: 10.3354/meps045225.

[22] Malouf, R. E., and Breese, W. P. 1977. "Seasonal
Changes in the Effects of Temperature and Water flow Rate on the Growth of Juvenile Pacific Oysters. Crassostrea gigas (Thunberg)." Aquaculture 12 (1): 1-13. doi: 10.1016/0044-8486(77)90042-4.

[23] Quayle, D. B. 1969. "Pacific Oyster Culture in British Columbia." Fish. Res. Board Can. Ottawa 169: 192.

[24] Nehring, S. 2006. NOBANIS-Invasive Alien Species Fact Sheet-Crassostrea gigas. From: Online Database of the North European and Baltic Network on Invasive Alien Species, NOBANIS.

[25] Frederico, M. M. B. 2007. "Assessment of the Aquacultural Potential of the Portuguese Oyster Crassostrea angulata.” Ph.D. thesis, Instituto de Ciências Biomédicas Abel Salazar ICBAS.

[26] Brown, O. B., and Minnett, P. J. 1999. MODIS Infrared Sea Surface Temperature Algorithm-Algorithm Theoretical Basis Document. Miami: University of Miami, 1-83.

[27] O'Reilly, J. E., Maritorena, S., Mitchell, B. G., Siegel, D. A., Carder, K. L., Garver, S. A., et al. 1998. "Ocean Color Chlorophyll Algorithms for SeaWiFS.” Journal of Geophysical Research 103: 24937-53. doi: 10.1029/98JC02160.

[28] Hu, C., Lee, Z., and Franz, B. 2012. "Chlorophyll a Algorithms for Oligotrophic Oceans: A Novel Approach Based on Three-Band Reflectance Difference." Journal of Geophysical Research: Oceans 117 (C1): C01011. doi: 10.1029/2011JC007395.

[29] Nechad, B., Ruddick, K. G., and Neukermans, G. 2009. "Calibration and Validation of a Generic Multisensor Algorithm for Mapping of Turbidity in Coastal Waters." In Proceedings of Remote Sensing of the Ocean, Sea Ice, and Large Water Regions, Vol. 7473, Berlin, Germany.

[30] Saaty, T. L. 1980. The Analytic Hierarchy Process. New York: McGraw Hill. International.

[31] Laing. I., and Spencer, B. E. 2006. Bivalve Cultivation: Criteria for Selecting a Site. Sience Serie Technical Report, No. 136. UK. CEFAS Project.

[32] Bernard, F. R. 1983. "Physiology and the Mariculture of Some Northeastern Pacific Bivalve Molluscs." Can. Spec. Publ. Fish. Aquat. Sci. 63: 1-24.

[33] Helm, M. M., and Millican, P. F. 1977. "Experiments in the Hatchery of Pacific Oyster Larvae (Crassostrea gigas Thunberg)." Aquaculture 11 (1): 1-12. doi: 10.1016/0044-8486(77)90149-1.

[34] Nell, J. A., and Holliday, J. E. 1988. "Effects of Salinity on the Growth and Survival of Sydney Rock Oyster (Saccostrea commercialis) and Pacific Oyster (Crassostrea gigas) Larvae and Spat.” Aquaculture 68 (1): 39-44. doi: 10.1016/0044-8486(88)90289-X.

[35] His, E., Robert, R., and Dinet, A. 1989. "Cobined Effects of Temperature and Salinity on Fed and Starved Larvae 

(Crassostrea gigas) Aquaculture in the Central Region of Vietnam

of the Mediterranean Mussel Mytilus galloprovincialis and the Japanese Oyster Crassostrea gigas." Marine Biology 100 (4): 455-63. doi: 10.1007/bf00394822.

[36] FAO/UNDP. 1990. Selected Papers on Mollusc Culture. UNDP/FAO Regional Seafarming Development and Demonstration Project (RAS/90/002).

[37] Byung, H. P., Mi, M. P., Bong, Y. K., Sung, B. H., and Seong, J. K. 1988. "Culture of the Pacific Oyster (Crassostrea gigas) in the Republic of Korea." Regional Seafarming Development and Demonstration Project (ras/86/024), Material for the Training Course on Oyster Culture conducted by the National Fisheries Research and Development Agency, Pusan, Republic of Korea.

[38] Kapetsky, J. M., and Aguilar-Manjarrez, J. 2013. "From Estimating Global Potential for Aquaculture to Selecting Farm Sites: Perspectives on Spatial Approaches and Trends." In Site Selection and Carrying Capacities for Inland and Coastal Aquaculture, edited by L. G. Ross, T. C. Telfer, L. Falconer, D. Soto and J. Aguilar-Manjarrez, 129-46. FAO/Institute of Aquaculture, University of Stirling, Expert Workshop, 6-8 December 2010. Stirling, the United Kingdom of Great Britain and Northern Ireland. FAO Fisheries and Aquaculture Proceedings No. 21. Rome, FAO, p. 282.

[39] Barillari, A., Boldrin, A., Pellizzato, M., and Turchetto, M. 1990. Condizioni ambientali nell'allevamento di Tapes philippinarum. Tapes philippinarum biologia e sperimentazione. Regione Veneto: E.S.A.V, 183-95. (in Corsican)

[40] Prema, D. 2013. Site Selection and Water Quality in
Mariculture. Teaching

Resource. http://eprints.cmfri.org.in/9707/.

[41] Rahul, K. P., Mishra, A. K., and Mukhopadhyay, A. 2006. "Remote Sensing and GIS Application for Assessment of Environmental Factors and Pearl Oyster Culture in Minicoy Island, Lakshaweep." In Proceedings of Symposium of ISPRS Commission IV, ISPRS Archives, Volume XXXVI Part 4.

[42] Pham, V. T., and Le, T. V. 2009. Establishing the Database on the Status of Environmental Water and Sedimentary Pollution Status along the Coastal Waters from Da Nang to Binh Thuan Province. Technical Report KC.09-24/06-10. (in Vietnamese)

[43] Tiensongrusmee, B., Pontjoprawiro, S., and Soedjarwo, I. 1986. Site Selection for the Culture of Molluscs. FAO/UNDP, INS/81/008/Manual/3, p. 17.

[44] Pilditch, C. A., and Grant, J. 1999. "Effect of Variations in Flow Velocity and Phytoplankton Concentration on Sea Scallop (Placopecten magellanicus) Grazing Rates." Journal of Experimental Marine Biology and Ecology 240 (1): 111-36. doi: 10.1016/S0022-0981(99)00052-0.

[45] Inglis, G. J., Hayden, B. J., and Ross, A. H. 2000. An Overview of Factors Affecting the Carrying Capacity of Coastal Embayments for Mussel Culture. Report for Ministry for the Environment, NIWA report CHC00/6931.

[46] Amemiya, I. 1928. "Ecological Studies of Japanese Oysters, with Special Reference to the Salinity of Their Habitats." Jour. Coll. Agric. Imp. Univ. Tokyo 9 (5): 333-82. 